\title{
Detection of anthropogenic dust using CALIPSO lidar measurements
}

\author{
J. P. Huang ${ }^{1}$, J. J. Liu ${ }^{1,2}$, B. Chen ${ }^{1}$, and S. L. Nasiri ${ }^{3}$ \\ ${ }^{1}$ Key Laboratory for Semi-Arid Climate Change of the Ministry of Education, College of Atmospheric Sciences, \\ Lanzhou University, Lanzhou, 730000, China \\ ${ }^{2}$ School of Mechanical and Instrument Engineering, Xi' an University of Technology, Xi'an 710048, China \\ ${ }^{3}$ Department of Atmospheric Science, Texas A\&M University, College Station, Texas, USA
}

Correspondence to: J. P. Huang (hjp@1zu.edu.cn)

Received: 5 March 2015 - Published in Atmos. Chem. Phys. Discuss.: 7 April 2015

Revised: 21 September 2015 - Accepted: 22 September 2015 - Published: 21 October 2015

\begin{abstract}
Anthropogenic dusts are those produced by human activities on disturbed soils, which are mainly cropland, pastureland, and urbanized regions, and are a subset of the total dust load which includes natural sources from desert regions. Our knowledge of anthropogenic dusts is still very limited due to a lack of data. To understand the contribution of anthropogenic dust to the total global dust load, it is important to identify it apart from total dust. In this study, a new technique for distinguishing anthropogenic dust from natural dust is proposed by using Cloud-Aerosol Lidar and Infrared Pathfinder Satellite Observation (CALIPSO) dust and planetary boundary layer (PBL) height retrievals along with a land use data set. Using this technique, the global distribution of dust is analyzed and the relative contribution of anthropogenic and natural dust sources to regional and global emissions are estimated. Results reveal that local anthropogenic dust aerosol due to human activity, such as agriculture, industrial activity, transportation, and overgrazing, accounts for about $25 \%$ of the global continental dust load. Of these anthropogenic dust aerosols, more than $53 \%$ come from semiarid and semi-wet regions. Annual mean anthropogenic dust column burden (DCB) values range from $0.42 \mathrm{~g} \mathrm{~m}^{-2}$, with a maximum in India, to $0.12 \mathrm{~g} \mathrm{~m}^{-2}$, with a minimum in North America. A better understanding of anthropogenic dust emission will enable us to focus on human activities in these critical regions and with such knowledge we will be more able to improve global dust models and to explore the effects of anthropogenic emission on radiative forcing, climate change, and air quality in the future.
\end{abstract}

\section{Introduction}

Dust accounts for some of the highest mass loadings in the atmosphere and plays an important role in modulating radiative forcing and climate via a number of complex processes (Huang et al., 2006a, b, 2014; Su et al., 2008). Although mineral dust is widely distributed and has a relatively large optical depth, the existing atmospheric dust load cannot be explained by natural sources alone (Tegen and Fung, 1995). The atmospheric dust load that originates from soils disturbed by human activities such as land use practices, which can be interpreted as "anthropogenic" dust (Tegen and Fung, 1995), can increase dust loading, which, in turn, affects the radiative forcing. It is critical to quantify the relative importance of different dust sources and the factors that affect dust emissions to understand the global dust cycle, including historical and future changes in dust emissions, as noted by Okin et al. (2011) and Bullard et al. (2011).

Anthropogenic dust primarily originates from agricultural practices (harvesting, ploughing, and overgrazing), changes in surface water (e.g., shrinking of the Caspian and Aral seas and Owens Lake), and urban and industrial practices (e.g., construction, cement production, and transportation) (Prospero et al., 2002). Over the last few decades, more frequent warmer and drier winters and springs in semi-arid and semiwet regions (Huang et al., 2012), as well as changes in vegetated land cover due to human activities, have likely increased anthropogenic dust emissions (Mahowald and Luo, 2003; Moulin and Chiapello, 2004; Tegen et al., 2004). Mulitza et al. (2010) demonstrated that the development of agriculture in the Sahel corresponded to a large increase in 
dust emission and deposition in the region. The current consensus is that up to half of the modern atmospheric dust load originates from anthropogenically disturbed soils (Tegen et al., 2004). Sokolik and Toon (1996) revealed that the direct solar radiative forcing from anthropogenic dust is very uncertain; thus, forcing from anthropogenically generated dust aerosols may be comparable to forcings from other anthropogenic aerosols. Therefore, a clear understanding of anthropogenic dust emissions is critical for predicting how changes in land use (and thus changes in land use policies) will influence dust emissions, loading, and deposition in the future (Okin et al., 2011).

However, assessments of the role of anthropogenic activity in the atmospheric dust cycle are limited by the accuracy of the available data sets (Mahowald et al., 2002). There are large uncertainties regarding the impact of anthropogenic activities on dust emissions (Sokolik and Toon, 1996). Understanding the radiative forcing caused by dust both directly (e.g., by disturbing soils, removing vegetation cover, or drying water bodies), and indirectly (e.g., by changing the climate or hydrological cycle) requires an improved data set. Although there are many examples of humans altering their environment and thereby causing an additional dust burden, it is challenging to separately quantify the natural and anthropogenic components of mineral aerosols (Sagan et al., 1979). Sokolik and Toon (1996) made the rough assumption that the dust production rate is linearly proportional to the dust source area and estimated the amount of anthropogenic mineral aerosols through assessment of the land area converted to desert by human activities. Tegen and Fung (1995) estimated the anthropogenic contribution to mineral dust to be 30 to $50 \%$ of the total dust burden in the atmosphere by using a three-dimensional atmospheric dust transport model. Later, Tegen et al. (2004) provided an updated estimate by comparing observations of visibility; they suggested that only 5 to $7 \%$ of mineral dust is derived from anthropogenic sources by calibrating a dust source model with emission indices from dust storm observations. There is limited understanding of anthropogenic dust emissions because of the difficulty of identifying and measuring them, which derives from strong heterogeneities in the sources (Mahowald et al., 2002). Ginoux et al. (2012) conducted one of the first studies that estimated anthropogenic dust emissions using observations. They estimated that $25 \%$ of dust is anthropogenic by using the Moderate-Resolution Imaging Spectroradiometer (MODIS) Deep Blue satellite products in combination with a land use fraction data set. A limitation of these products is that they can be retrieved only over surfaces that are bright at visible wavelengths, excluding forests and ocean surfaces. Additionally, MODIS products do not include vertical distribution information and therefore cannot readily exclude natural dust aerosols from deserts or marine sea salt aerosols that are transported over anthropogenic sources.

The Cloud-Aerosol Lidar and Infrared Pathfinder Satellite Observations (CALIPSO) satellite can actively remotely sense cloud and aerosol vertical profiles (Winker et al., 2007; $\mathrm{Hu}$ et al., 2007a, b, 2009; Chen et al., 2010). CALIPSO's measurement of vertical resolution and polarization ratios can provide new insights into global anthropogenic dust emissions. In this study, we develop a new technique for detection of anthropogenic dust emissions that uses CALIPSO lidar measurements and analyzes their global distribution. Section 2 presents the data used in this study, and the method for separating anthropogenic from natural dust is outlined in Sect. 3. Section 4 discusses the calculation of the anthropogenic dust column burden (DCB). Section 5 presents the global distribution of anthropogenic dust. Finally, the conclusions are presented in Sect. 6.

\section{Data}

\subsection{CALIPSO data}

This study relies on the CALIPSO Cloud-Aerosol Lidar with Orthogonal Polarization (CALIOP) for dust detection. CALIOP acquires vertical profiles of elastic backscatter at two wavelengths (532 and $1064 \mathrm{~nm}$ ) and linear depolarization at $532 \mathrm{~nm}$ from a near-nadir viewing geometry during both the day and the night (Winker et al., 2007; Hu et al., 2007a, b, 2009; Chen et al., 2010). This study uses Level 1 backscatter, depolarization ratio, and color ratio profiles along with the Level 2 Vertical Feature Mask (VFM) products and $5 \mathrm{~km}$ Aerosol Profile Products. The depolarization ratio is a useful indicator for identifying non-spherical particles, and it can distinguish between atmospheric dust and spherical aerosols (Liu et al., 2004; Sun et al., 2013). The CALIPSO algorithm classifies aerosol layers that have volume depolarization ratio $\left(\delta_{\mathrm{V}}\right)$ greater than 0.075 as dust (Omar et al., 2009; Mielonen et al., 2009). Mielonen et al. (2009) also confirmed that classification of dust is more reliable than classification of fine aerosols because depolarization ratio can be used to distinguish non-spherical aerosols from spherical ones, while the color ratio is sensitive mainly to particle size.

The CALIPSO Level 2 lidar VFM product (Liu et al., 2004; Vaughan et al., 2004) provides information about cloud and aerosol layer boundaries and positions. In CALIPSO version 3 VFM data, the cloud aerosol discrimination (CAD) algorithm separates clouds and aerosols based on multidimensional histograms of scattering properties (e.g., intensity and spectral dependence), that is, the altitude- and latitude-dependent feature integrated color ratio, $\chi^{\prime}$, the layer-integrated volume depolarization ratio, $\delta_{\mathrm{v}}$, and the feature mean attenuated backscatter coefficient, $\beta_{532}^{\prime}$ (Liu et al., 2010). A parameter (CAD score) indicates the confidence at which a feature (aerosol or cloud) can be distinguished using the CAD algorithm. Liu et al. (2010) revealed that the feature classification is more reasonable if a higher magnitude of the absolute value of CAD score is used and suggested applying 
a CAD score larger than 70 . In our study, we selected a features where the $|\mathrm{CAD}| \geq 70$ as well.

The Level 2 Aerosol Profile Product (Young and Vaughan, 2009) provides profiles of particle extinction coefficient and backscatter and additional profile information. In addition, the CALIPSO extinction quality control (QC) flags were also provided. Extinction $\mathrm{QC}=0$ (the lidar ratio is unchanged during the extinction retrieval) and $\mathrm{QC}=1$ (if the retrieval is constrained) are chosen in this paper, which are used to calculate optical depth by integrating extinction coefficients. Chen et al. (2013) noted that the impact of the screening procedure in this specific case is negligible.

\subsection{Land cover data}

The Collection 5.1 MODIS global land cover type product (MCD12C1) from 2011 is used in this study to provide anthropogenic dust source types. The $\mathrm{MCD} 12 \mathrm{C} 1$ product has $0.05^{\circ}$ spatial resolution, includes 17 different surface vegetation types, and was developed by the International Geosphere-Biosphere Programme data (IGBP) (Loveland and Belward, 1997; Friedl et al., 2010). It provides the dominant land cover type as well as the sub-grid frequency distribution of land cover classes within each $0.05^{\circ}$ cell. Because we are focusing on sources of anthropogenic dust in this paper, we limit our study to three agricultural surface types: croplands, grasslands, and cropland mosaics. Cropland mosaics are lands with a mosaic of croplands less than $60 \%$ of the landscape (Friedl et al., 2002). Because urban environments can also be sources of anthropogenic dust, we get information about the extent of urban areas from the Global Rural-Urban Mapping Project (GRUMP) v1 (Schneider et al., 2010) data set. In Fig. 1, we summarize the geographical distribution of the anthropogenic dust source types described above. The colors indicate the locations of the four different anthropogenic dust source types: red represents urban areas, orange represents grassland, yellow represents cropland, and green represents cropland mosaics. The four black rectangles denote four regions that will be emphasized later: eastern China, India, North America, and Africa.

\subsection{Precipitation data}

Anthropogenic dust emissions depend on soil moisture content and therefore on precipitation and climate state. In this study, we use precipitation as a proxy for climate state. The University of East Anglia Climate Research Unit (CRU) Global Climate Dataset provides the monthly mean precipitation climatologies for global land areas, excluding Antarctica (New et al., 1999), which is used in this study. The data set is based on analysis of over 4000 individual weather station records and is provided at $0.5^{\circ}$ latitude and longitude resolution. The CRU Global Climate Dataset temperature and precipitation estimates were made for $80-100 \%$ of the land surface (Mitchell and Jones, 2005). In this study, the monthly

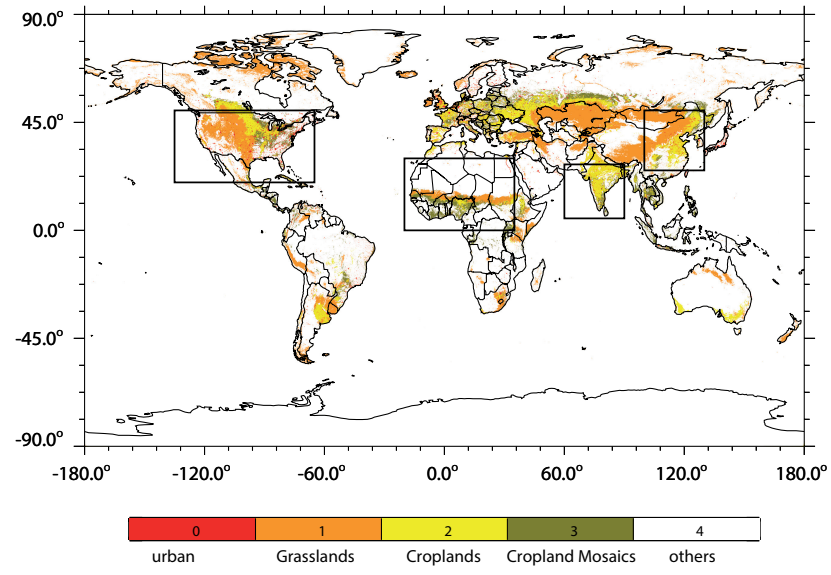

Figure 1. Global anthropogenic land cover (including urban, cropland, and pastureland) distribution retrieved by combing MODIS and GRUMP data.

mean climatology was calculated relative to the average for the period 1961-1990.

\section{Calculation of dust column burden (DCB)}

Based on the detection methods described above, we are able to identify anthropogenic dust and calculate anthropogenic dust column burden as a subset of the global dust column burden. First, we used the dust extinction coefficient through the parameter "Atmospheric Volume Description" which is used to discriminate between aerosols and clouds in the CALIPSO Level 2 aerosol extinction profile products. Then, dust extinction coefficients with higher confidence levels $(|\mathrm{CAD}| \geq 70)$ (Liu et al., 2010) and quality control $(\mathrm{QC}=0$ or $\mathrm{QC}=1$ ) based on the study of Chen et al. (2013) were selected. Therefore, dust optical depth (DOD, $\tau$ ) can be calculated by integrating the $\mathrm{CAD}$ and $\mathrm{QC}$ quality-controlled extinction coefficient of dust aerosol over the height of the dust layer.

After calculating global total DOD $\left(\tau_{\mathrm{t}}\right)$ and anthropogenic $\operatorname{DOD}\left(\tau_{\mathrm{a}}\right)$ from the CALIPSO profile products between January 2007 and December 2010, we were able to calculate dust column burdens. The conversion from dust optical depth $(\tau)$ to dust column mass burden $(M)$ was calculated following Ginoux et al. (2001):

$M=\frac{4}{3} \frac{\rho r_{\text {reff }}}{Q_{\text {ref }}} \tau=\frac{1}{\varepsilon} \tau$,

where $r_{\text {eff }}$ is the dust effective radius, $\rho$ is the density of dust, $Q_{\text {ext }}$ is the dust extinction efficiency, and $\varepsilon$ is the mass extinction efficiency. Ginoux et al. (2012) used daily global DOD from MODIS Deep Blue aerosol products and converted it into column burden. In this study, we follow those empirical values taken by Ginoux et al. (2012) and assume $r_{\text {eff }}=1.2 \mu \mathrm{m}, \rho=2600 \mathrm{~kg} \mathrm{~m}^{-3}, Q_{\text {ext }}=2.5, \varepsilon=0.6 \mathrm{~m}^{2} \mathrm{~g}^{-1}$, 
and $\tau$ is the dust optical depth derived from the CALIPSO retrievals.

\section{Dust detection and identification methods}

It is a challenge to distinguish the anthropogenic dust component from natural dust (Sagan et al., 1979; Sokolik and Toon, 1996) due to the indirect nature of satellite-based measurement data. In 2012, Ginoux et al. (2012) proposed a method to detect anthropogenic dust by using MODIS Deep Blue products, but MODIS, a passive instrument, has limited accuracy over relatively bright land surfaces. In order to obtain more accurate and comprehensive results, we developed a new method to separate natural and anthropogenic dust and assessed anthropogenic impacts on dust emissions at the global scale by using CALIPSO measurements.

Figure 2 shows a schematic of dust sources and vertical and horizontal transport processes underlying our approach for separating anthropogenic dust from natural dust. The yellow dots represent dust aerosol in the atmosphere; the arrows and red wavy lines indicate lifting and turbulence, respectively. It illustrates that natural dust from deserts can undergo long-range transport to other regions by lifting through the planetary boundary layer (PBL) to the free troposphere, as confirmed by Chen et al. (2013). Horizontal transport of natural dust aerosols occurs mainly above the PBL (Jordan et al., 2010; Yu et al., 2012). Only a small amount of this dust enters and remains within the PBL. However, it is this fraction that may be most relevant to air quality (Yu et al., 2012). Dusts from other land surface types and pollution sources are predominately trapped in the PBL where industrial and commercial activities, except for air travel, are conducted (Stull, $1988,2000)$. We go through four steps to discriminate anthropogenic dust from natural dust in the CALIPSO data. The first step is to detect the total dust load (both natural and anthropogenic).The second step is to determine the source region of the dust. The third step is to determine the height of PBL, and the final step is to determine which dust is anthropogenic dust i.e., the subset of the total dust within PBL.

\subsection{Step 1: Total dust detection}

Aerosol subtypes are stored in the parameter "Feature Classification Flags" of CALIPSO VFM data. Therefore, dust aerosols are identified by Feature Classification Flags in this paper. We only use dust aerosol features for which there is high confidence, i.e., absolute values of CAD score greater than 70. Then, dust aerosol extinction coefficients are integrated under the condition of extinctions $\mathrm{QC}=0$ and $\mathrm{QC}=1$, which are chosen from CALIPSO's aerosol profile product. Next, we calculated dust aerosol optical depth as well as dust column burden $\left(\mathrm{g} \mathrm{m}^{-2}\right)$ in Eq. (1).

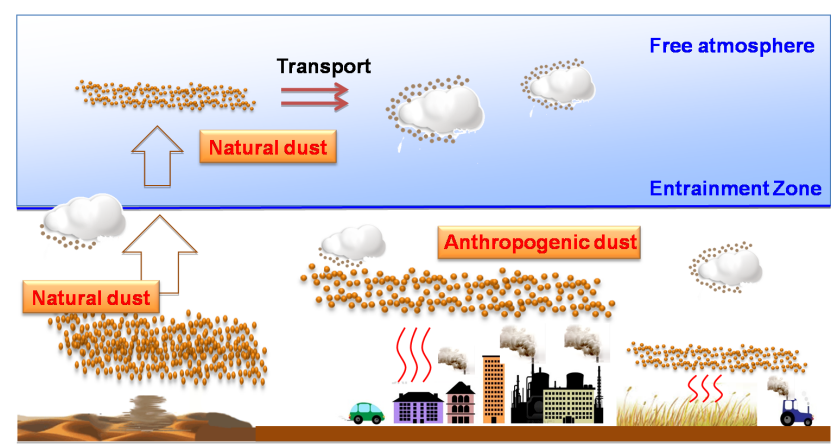

Figure 2. A schematic figure for the detection process of anthropogenic dust.

\subsection{Step 2: Selection of source regions of anthropogenic dust}

As stated previously, anthropogenic dust mainly comes from harvesting, ploughing, overgrazing, construction, traffic, etc. We assume that anthropogenic dust will typically be emitted from cropland, grasslands, and urban surfaces (referred to as "anthropogenic surface"), will have thinner dust aerosol layers, will be predominately trapped in PBL, and will rarely be lifted into the free atmosphere by wind and turbulence. Therefore, we restrict our source regions to the urban, grassland, cropland, and mosaic cropland surfaces from the MODIS and GRUMP data sets, as seen in Fig. 1.

\subsection{Step 3: Determination of PBL height}

In this step, we determine and use PBL height to exclude long-distance transport of dust aerosol from dust sources above the anthropogenic surface described above, so it is important to accurately determine PBL height to separate out the anthropogenic dust.

We can use CALIPSO to determine PBL height because, in general, the PBL is capped by a temperature inversion that tends to trap moisture and aerosols. The gradient of backscatter seen by lidar is almost always associated with this temperature inversion and the simultaneous decrease in moisture content (Palm et al., 1998; Melfi et al., 1985). Thus, the definition of the PBL top as the location of the maximum aerosol scattering gradient is analogous to the more conventional thermodynamic definition. McGrath-Spangler and Denning (2012) revealed that the Modern-Era Retrospective Analysis for Research and Applications (MERRA) PBL depths are within $25 \%$ of the estimates derived from the maximum standard technique (Jordan et al., 2010) by CALIPSO, which is better than radiosonde estimates of space/time average PBL depth (Angevine et al., 1994).

We modified the maximum standard technique developed by Jordan et al. (2010) and derived global PBL heights using this method, which are consistent with results of McGrath-Spangler and Denning (2012). And, we found that 


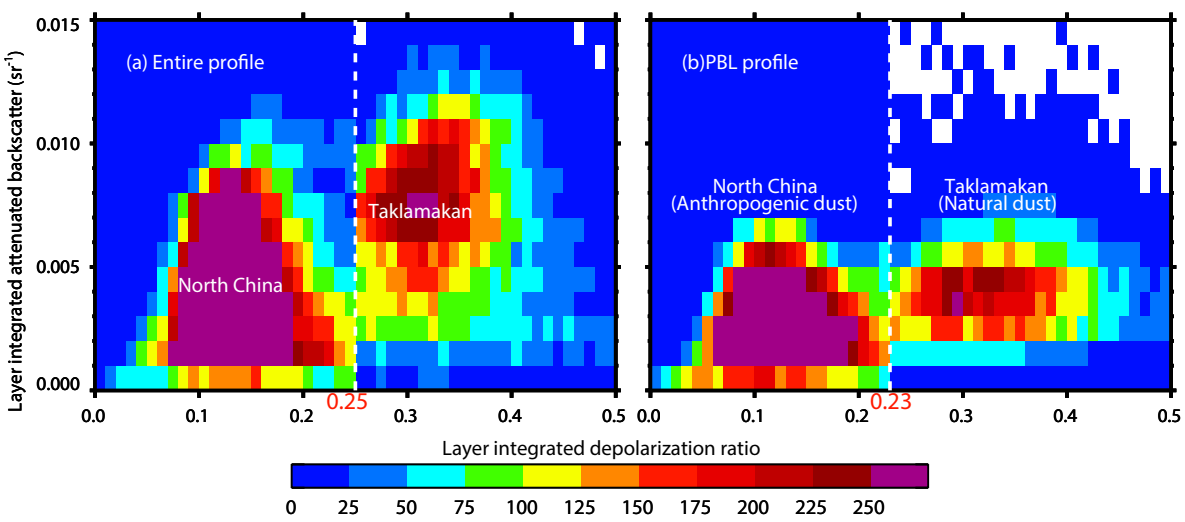

Figure 3. The relationship between the layer-integrated depolarization ratio and the layer-integrated attenuated backscatter coefficient for anthropogenic dust (North China) and natural dust (Taklamakan) for (a) the entire profile, and (b) the PBL profile.

this technique compared favorably to the ground-based lidar at the Semi-Arid Climate and Environment Observatory of Lanzhou University (SACOL) (Huang et al., 2008) with a correlation coefficient of 0.73 (Liu et al., 2015).

\subsection{Step 4: identification of anthropogenic dust within PBL}

The final step is to identify the anthropogenic dust within the PBL. Two parameters, the layer integrated depolarization ratio $\delta^{\prime}$ and the layer integrated attenuated backscatter coefficient $\gamma^{\prime}$, can be used to explore the difference in optical properties between natural dust and anthropogenic dust. As an illustration of the process and resulting output of this step, we chose two typical areas based on dust optical depth $(\tau)$, population density, and land cover distribution, to represent sources of anthropogenic dust (North China: 35.0$39.0^{\circ} \mathrm{N}, 114.0-118.0^{\circ} \mathrm{E}$ ) and natural dust source (Taklamakan: $38.0-40.0^{\circ} \mathrm{N}, 78.0-83.0^{\circ} \mathrm{E}$ ). Because spring (March to May) is the most active season for dust emission in the Taklamakan region, 4 years (2007 through 2010) of spring daytime CALIPSO measurements were used to look at the optical properties of natural dust aerosol. Because anthropogenic dust has little seasonal dependence and natural dust is at its minimum during autumn in northern China, we used 4 years (2007 through 2010) of autumn measurements to look at the optical properties of anthropogenic dust. For these two seasons, the statistical distribution of the layerintegrated $\delta^{\prime}$ and $\gamma^{\prime}$ for both anthropogenic dust and natural dust from the entire profile and within the PBL, respectively, was constructed by summing occurrences within grid boxes of $\Delta \delta^{\prime}-\Delta \gamma^{\prime}$, measuring 0.01 by $0.001 \mathrm{sr}^{-1}$.

In Fig. 3a, we can see that a threshold of $\delta^{\prime}=0.25$ can be used to discriminate dust based on the set of entire height profiles from the Taklamakan and North China. Figure $3 \mathrm{~b}$ shows that a lower threshold of $\delta^{\prime}=0.23$ can be used to separate anthropogenic dust from natural dust within the PBL. The larger threshold value for the entire profile com-

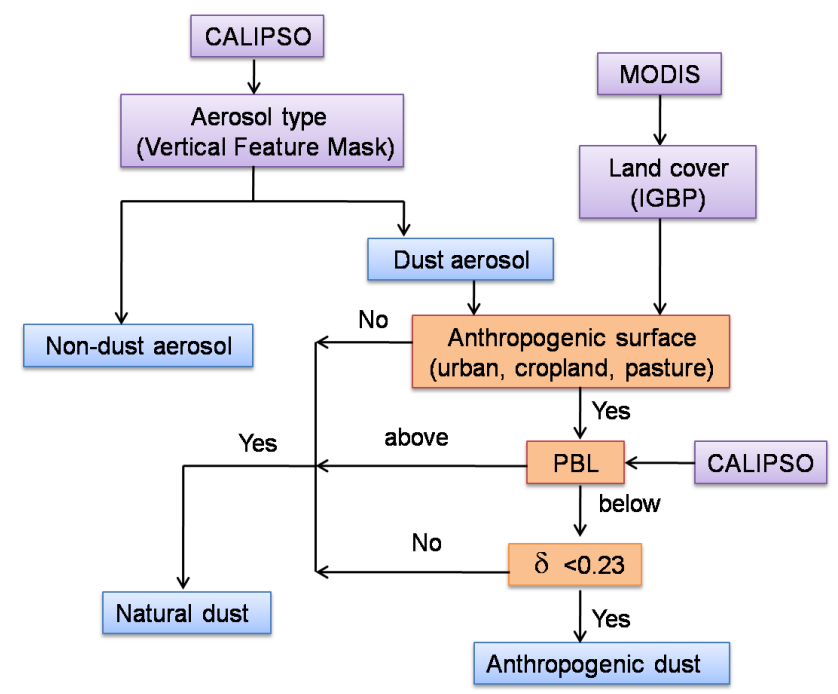

Figure 4. Flow chart of anthropogenic dust detection by combing CALIPSO and land cover data set provided by MODIS.

pared to the PBL is mainly due to the fact that natural dust transport above the PBL in North China leads to a larger depolarization ratio. Furthermore, anthropogenic dust has lower layer-integrated attenuated backscatter because anthropogenic dust produced by human activities is generally mixed with other more spherical aerosol types within the PBL, which has lower non-spherical particle. Natural dust is more non-spherical than anthropogenic dust, so anthropogenic dust has a lower layer-integrated depolarization ratio than natural dust.

Therefore, anthropogenic dust could be accurately distinguished from natural dust through the above steps. Inevitably, there are some misclassifications of anthropogenic and natural dust owing to anthropogenic dust mixed with natural dust above and below the PBL. This problem should be kept in mind in the following results and discussion. Quantitatively, 

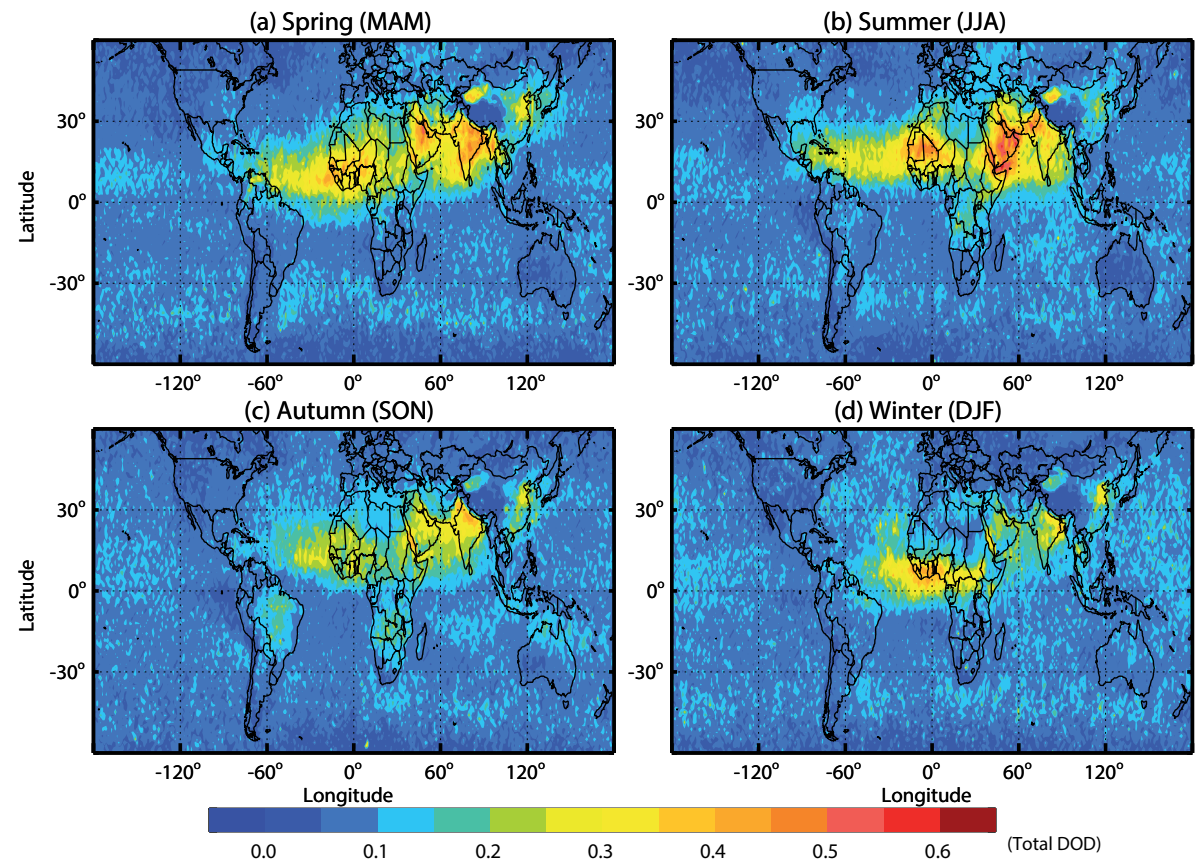

Figure 5. Global seasonal distributions of total (including polluted dust) dust optical depth derived from CALIPSO measurements (20072010) for spring-winter, (a)-(d), respectively.

$\sim 9.6 \%$ of anthropogenic dust is misclassified as natural dust and $8.7 \%$ of natural dust is misclassified as anthropogenic dust within the PBL mixed with the anthropogenic dust, respectively.

A detailed flow chart of the anthropogenic dust detection algorithm is shown in Fig. 4.

\section{Results}

The global distributions of seasonal mean and total DOD with $1.25^{\circ} \times 1.25^{\circ}$ resolution derived from CALIPSO measurements for 2007-2010 are presented in Fig. 5. Dust covers a larger area in the Northern Hemisphere than in the Southern Hemisphere. The Taklamakan and Gobi deserts in China (Qian et al., 2002; Huang et al., 2007, 2008) and the deserts on the Indian subcontinent (Middleton, 1986) are major dust source regions that are subordinate only to North Africa and the Arabian Peninsula (Prospero et al., 2002; Z. Liu et al., 2008). These major dust sources are located in the broad "dust belt" that stretches from the western coast of North Africa to China, covering the Sahara and Sahel regions, the Arabian Peninsula, northern India, the Tarim Basin and the Gobi Desert (Herman et al., 1997; Prospero et al., 2002; D. Liu et al., 2008; J. Huang et al., 2014; Z. Huang et al., 2010). The dust sources are usually associated with topographical basins in these arid regions, on land adjacent to high mountainous or plateau regions or in intermountain basins, as discussed in detail by Prospero et al. (2002). The annual rainfall in these dust source regions is generally low, less than $200-250 \mathrm{~mm}$. Significant seasonal variation in the DOD is illustrated in panels (a) through (d) of Fig. 5. Dust outbreaks are most active in this dust belt during the spring and summer. In North Africa and the Arabian Peninsula, summer is the most active season, whereas spring is the most active season in the Indian subcontinent and the Taklamakan region. In the Arabian Peninsula, the Indian subcontinent, and Taklamakan, dust activities weaken rapidly in autumn, reaching a minimum in winter. Figure 5 illustrates a major dust transport pathway, in which the transatlantic transport of North African dust stretches the "dust belt" towards the North American continent. North African dust is transported across the Atlantic throughout the year, although spring and summer are the most active seasons and autumn is the least active. Figure 5 also shows that the Hexi Corridor is a transport pathway in East Asia, although it is clearly subordinate to the North Atlantic pathway.

Using Eq. (1), we calculated the global annual mean total DCB to be $79.3 \mathrm{Tg}$. The global seasonal mean values, which are 81.5 (spring), 81.0 (summer), 73.7 (autumn), and 77.5 (winter) $\mathrm{Tg}$, indicate that the dust burden in the atmosphere is greater during the spring and summer. According to Huneeus et al. (2011), the global annual mean dust burden values from 14 models range from 6.8 to $29.5 \mathrm{Tg}$. These values are far less than our results, possibly because we include air masses with both pollution aerosols and dust, thereby accounting for episodes in which dust mixes with smoke from biomass burning, urban pollution, and sea salt aerosols (Omar et al., 2009). In these cases the depolarization ratio is dominated by the 


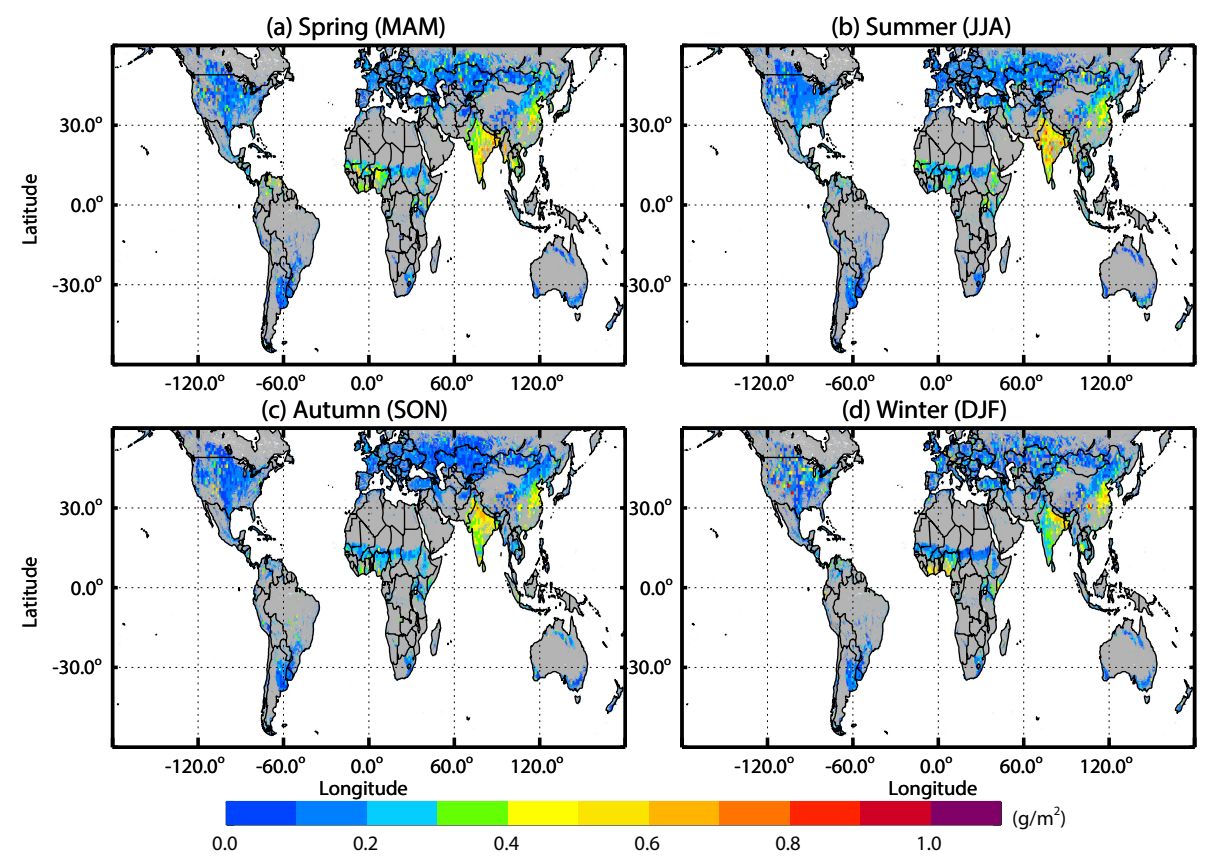

Figure 6. Global seasonal distributions of mean anthropogenic dust column burden (2007-2010) for spring-winter, (a)-(d), respectively. The gray areas represent non-anthropogenic dust source over land.

dust component, thus causing the entire mixture to be classified as dust and imparting greater values to our DCB values.

Figure 6 illustrates the global distribution of the seasonal mean anthropogenic DCBs. The global seasonal mean anthropogenic DCBs are 7.0 (spring), 6.9 (summer), 6.1 (autumn), and 6.0 (winter) Tg, respectively. This pattern differs from the seasonal pattern of natural DOD $\left(\tau_{\mathrm{n}}\right)$; the anthropogenic DCB has minimal seasonal variation because anthropogenic dust emissions are controlled by human activities and urban pollutants. Greater DCBs occurred in eastern China, India, and North Africa during all seasons. These greater DCBs are related to higher population densities in eastern China and India and biomass burning throughout the year in Africa when farmers prepare land for the agricultural season and grazing (Justice et al., 1996). The global annual mean anthropogenic DCB is $6.7 \mathrm{Tg}$, which accounts for $8.4 \%$ of the total global DCB. To avoid the impact of dust on the ocean, we only calculated global continental dust aerosols. We found that anthropogenic dust sources account for $24.8 \%$ of total continental dust sources (including polluted dust). There are two reasons for the difference between our results and those of Ginoux et al. (2012): first, the MODIS Deep Blue algorithm only retrieves the DOD over bright surfaces (excluding forest and oceans), thus leading to a lower dust burden. Second, MODIS data products lack vertical information; therefore, they cannot extract natural dust from deserts transported over anthropogenic source regions, and thus they tend to yield larger results.

Figure 7 shows the global distribution of the anthropogenic dust percentage of the total DCB over land. This

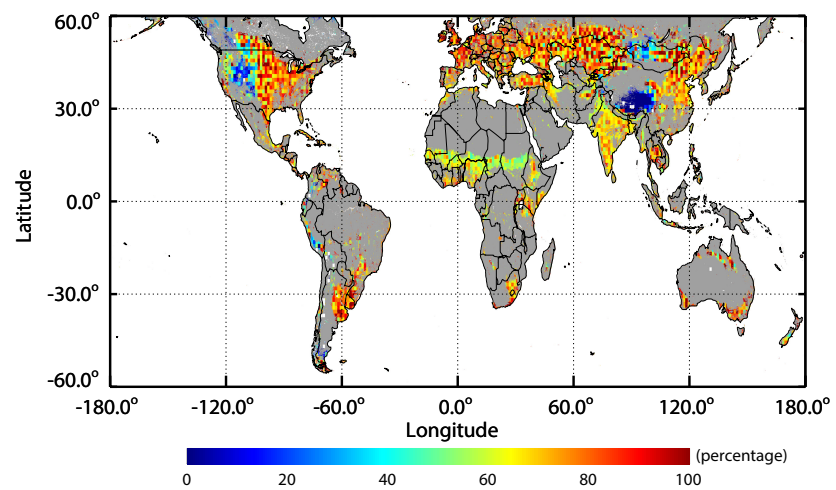

Figure 7. Global distributions of the percentage of anthropogenic dust column burden account for total dust column burden.

figure illustrates the significance of human activities on dust in many areas. Several features are evident in these maps. Highly populated or intensively cultivated agricultural regions, such as eastern North America, India, eastern China, and Europe, all have anthropogenic dust percentages of greater than $60 \%$. Lower percentages occur over places such as western North America, particularly the Great Basin, and North Africa, where less human activity leads to fewer anthropogenic dust aerosols.

Figure 8 compares the global DCB as a function of climatological mean precipitation for spring, summer, autumn, and winter. Although soil moisture is also related to the surface temperature, the long-term mean precipitation is the 
Table 1. Summary of anthropogenic dust annual mean statistics by climate region - anthropogenic dust optical depth (ADOD); total regional area; regional anthropogenic dust column burden (DCB) (and percent contribution by region); regional dust column burden (DCB); and percent contribution to regional DOD.

\begin{tabular}{lrrrrr}
\hline Region & Mean anthropogenic DOD & Area $\left(\mathrm{km}^{2}\right)$ & Anthropogenic DCB (Tg) & DCB (Tg) & Contribution to regional DOD $(\%)$ \\
\hline Wet & 0.12 & $1.77 \times 10^{7}$ & $2.48(41.2)$ & 3.09 & 80.3 \\
Semi-arid \& semi-wet & 0.07 & $2.46 \times 10^{7}$ & $3.16(52.5)$ & 4.67 & 67.7 \\
Arid & 0.06 & $1.21 \times 10^{6}$ & $0.38(6.3)$ & 0.56 & 67.9 \\
\hline
\end{tabular}

simplest index for classifying climate regions. The mean precipitation varies from less than $100 \mathrm{~mm} \mathrm{yr}^{-1}$ to a maximum of $2000 \mathrm{~mm} \mathrm{yr}^{-1}$ in Fig. 8, and the interval value is $100 \mathrm{~mm} \mathrm{yr}^{-1}$. The average anthropogenic DCB that corresponds to each precipitation interval is plotted. Figure 8 shows that anthropogenic dust mainly comes from semi-arid and semi-wet regions over the entire year. Semi-arid regions are transition zones between arid and semi-wet regions. They are defined as areas in which the precipitation is less than the potential evaporation, and are characterized by high temperatures $\left(30-45^{\circ} \mathrm{C}\right)$ during the hottest months. The annual mean precipitation ranges from 200 to $600 \mathrm{~mm} \mathrm{yr}^{-1}$ in semi-arid regions. Semi-wet regions cover considerable parts of eastern North America, Europe, and central China, with precipitation ranging from 600 to $800 \mathrm{~mm} \mathrm{yr}^{-1}$. The total anthropogenic DCB is greater in spring and summer than in autumn and winter. This difference is most significant in arid regions. There is almost no anthropogenic dust observed in arid regions because of minimal agricultural and human activities and urban pollution. Table 1 presents the annual mean anthropogenic DOD $\left(\tau_{\mathrm{a}}\right)$, total area, total anthropogenic DCB, and the percentage contribution to the total DCB from wet, combined semi-arid and semi-wet, and arid regions. In wet regions the mean DOD is 0.12 , and the anthropogenic contribution to the total DCB in wet regions is $80.3 \%$. This value is greater than the anthropogenic contributions from combined semi-arid and semi-wet regions, and arid regions, thus revealing that anthropogenic dust plays an important role in determining the total amount of dust because the frequency of total natural dust events (suspended dust, blowing dust, and dust storms) is lower in wet regions. Table 1 suggests that anthropogenic dust aerosols from the combined semiarid and semi-wet regions contribute $52.5 \%$ to the total anthropogenic dust aerosols over all three regions. The more frequent occurrence of anthropogenic dust emissions over semi-wet and semi-arid regions may be related to greater human activities and poor ecological practices in those regions.

Figure 9 shows the regional distribution of the annual mean anthropogenic DCB derived from CALIPSO measurements in four regions: eastern China, India, North America, and North Africa. Table 2 lists their latitude and longitude ranges, the area and percentage of each region that is considered to contribute to anthropogenic dust emissions, and the annual mean anthropogenic DCB of the regions. In India,

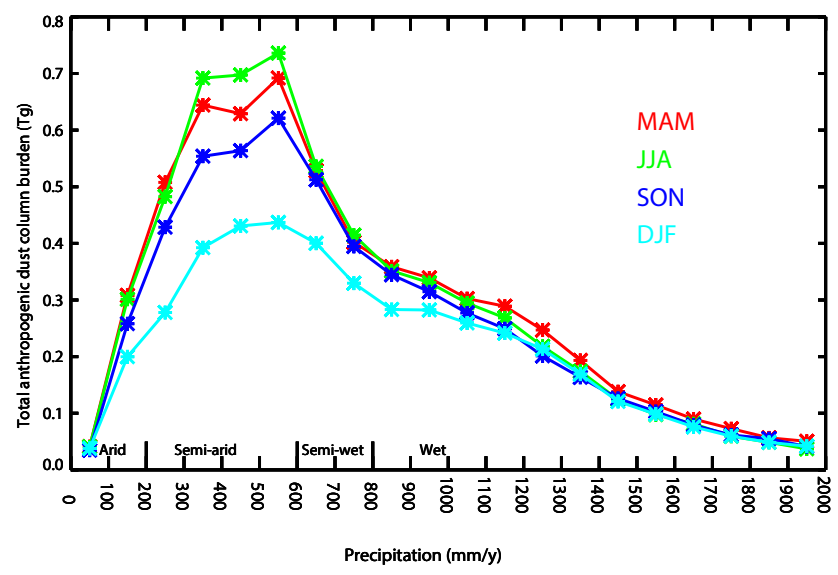

Figure 8. Comparisons of dust column burden as function of climatological mean precipitation for different four seasons (spring, summer, autumn, and winter) of global anthropogenic land cover. The precipitation interval is $100 \mathrm{~mm} \mathrm{yr}^{-1}$.

anthropogenic dust sources are distributed relatively evenly over the region; the anthropogenic dust source area is $70.2 \%$ of the total area that is characterized by intense agricultural and human activities (Prasad et al., 2007). In North Africa, we note in Figs. 9 and 10 that the southern Sahel dust sources are overwhelmingly anthropogenic and are associated with aerosols from biomass burning. There is a clear separation between natural dust sources in the Sahara and anthropogenic dust in the southern Sahel. The area dominated by anthropogenic dust sources is only $21.5 \%$ of the total area i.e., most of the area is dominated by natural dust sources. Figure 9 also shows that anthropogenic dust sources in eastern China are mostly confined to areas in northeastern China, the North China Plain, and Inner Mongolia. The largest anthropogenic DCBs are located over the North China Plain. This result is consistent with the conclusions of Wang et al. (2006), who found that dust storm frequency does not exceed 8 days per year in northern China, even where there are high levels of human activity. In Mongolia, there are dozens of small anthropogenic dust sources associated with pasturelands or grasslands. In North America, most dust sources are centered in two eastern areas, the Great Plains and the Upper Mississippi Valley and also in the Great Basin to the west of the continental divide. A major difference from the results 
Table 2. Description of dust study areas - latitude and longitude ranges; area and percent of the region considered to contribute to anthropogenic dust emissions; and annual mean anthropogenic dust column burden (ADCB) of the regions considered in this study.

\begin{tabular}{lrrrr}
\hline Region & Longitude range & Latitude range & Anthropogenic area km ${ }^{2}(\%)$ & Mean ADCB $\left(\mathrm{g} \mathrm{m}^{-2}\right)$ \\
\hline Eastern China & $100.0-130.0^{\circ} \mathrm{E}$ & $25.0-50.0^{\circ} \mathrm{N}$ & $3.71 \times 10^{6}(63.0)$ & 0.17 \\
India & $60.0-90.0^{\circ} \mathrm{E}$ & $5.0-27.5^{\circ} \mathrm{N}$ & $1.98 \times 10^{6}(70.2)$ & 0.42 \\
North America & $135.0-65.0^{\circ} \mathrm{W}$ & $20.0-50.0^{\circ} \mathrm{N}$ & $5.56 \times 10^{6}(54.0)$ & 0.09 \\
North Africa & $20.0^{\circ} \mathrm{W}-35.0^{\circ} \mathrm{E}$ & $0.0-30.0^{\circ} \mathrm{N}$ & $3.40 \times 10^{6}(21.5)$ & 0.26 \\
\hline
\end{tabular}
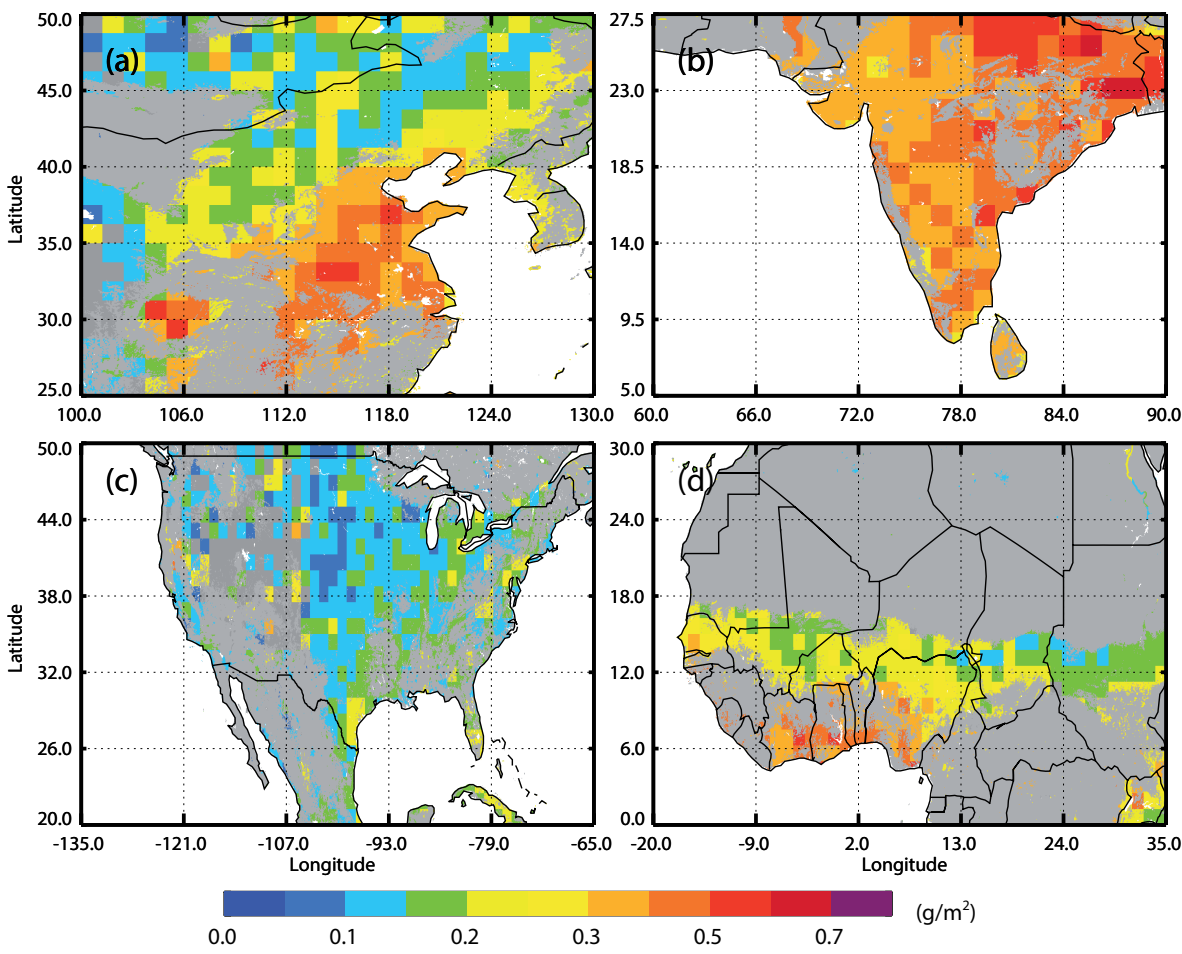

Figure 9. Regional distribution of annual mean anthropogenic dust column burden derived from CALIPSO measurements (2007 through 2010) for (a) eastern China, (b) India, (c) North America, and (d) North Africa.

of Ginoux et al. (2012) is that on the east side of the divide, anthropogenic and natural dust sources are intertwined, and on the west side of the divide, the sources are predominantly natural rather than anthropogenic. The largest anthropogenic DCBs are distributed over southeastern North America.

A histogram that illustrates the relative contribution of anthropogenic and natural dust sources over anthropogenic dust source surfaces for the four study regions is shown in Fig. 10. The annual mean anthropogenic DCB values range from a maximum of $0.42 \mathrm{~g} \mathrm{~m}^{-2}$ in India to a minimum of $0.12 \mathrm{~g} \mathrm{~m}^{-2}$ in North America, including $0.23 \mathrm{~g} \mathrm{~m}^{-2}$ in eastern China and $0.24 \mathrm{~g} \mathrm{~m}^{-2}$ in North Africa. The anthropogenic dust contributions to regional emissions from eastern China and India are 91.8 and $76.1 \%$, respectively, followed by North America, with $73.9 \%$. In recent years, urbanization and human activities have increased in eastern China; thus, its annual mean contribution of anthropogenic dust is the largest, approxi- mately $91.8 \%$. In Africa, the Sahara Desert is a rich source of natural dust. Although the anthropogenic dust contribution is minimal, it is greater than in North America and eastern China. A lower amount of urban construction and human activity in North America means that both its anthropogenic dust content and contribution are the lowest of the four regions. A possible explanation for the above phenomenon is that eastern China and India have larger population densities and thus more intense agricultural and human activities.

\section{Discussion and conclusions}

Emission of soil and mineral dust particles from the Earth's surface is a small-scale process that has global consequences (Okin et al., 2011), such as cloud formation (Huang 2006b, 2010, 2014), anthropogenic carbon dioxide emission, snow albedo changes (Huang et al., 2011), and land use changes 


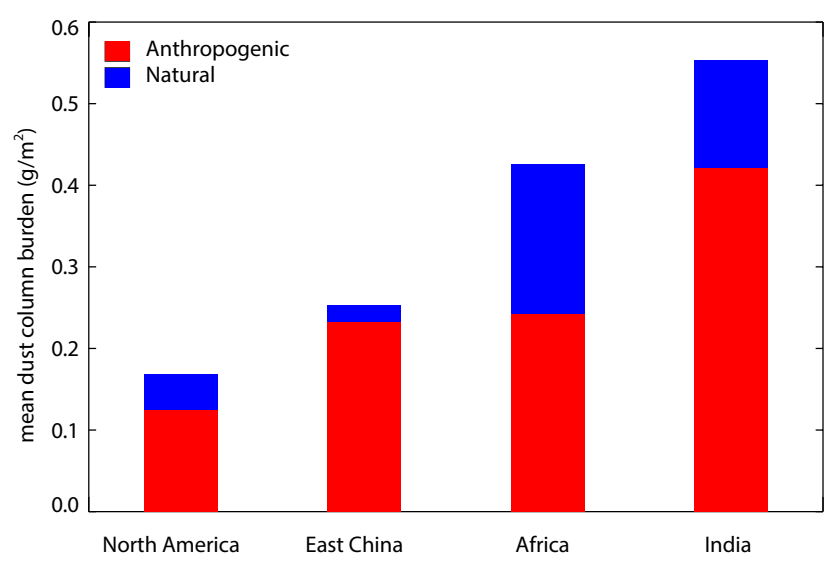

Figure 10. Anthropogenic (red) and natural (blue) mean dust column burdens and percentages in four regions (eastern China, India, North America and Africa).

(Sokolik et al., 2011). Dust emissions are affected by climate variability and in turn can impact climate, air quality, and human health (Ginoux et al., 2012). Global dust aerosols contain not only locally emitted anthropogenic aerosols (including agricultural dust and industrial black carbon) but also natural dust from deserts. Dust emissions from anthropogenic activities could account for a large proportion of global dust emissions, but quantifying anthropogenic dust emissions is subject to large uncertainty (Sokolik and Toon, 1996). In this paper, we have developed an algorithm to detect anthropogenic dust based on CALIPSO measurements and the MODIS land cover data set. Using this algorithm, we have determined the contribution of anthropogenic dust to the total global dust load.

We conducted a case study to test our algorithm using CALIPSO data for the Taklamakan Desert and northern China, both of which are known natural and anthropogenic dust source regions, respectively. We found that anthropogenic dust has a layer-integrated depolarization ratio that is less than that of natural dust. This difference exists because anthropogenic dust produced by human activities is generally mixed with other types of aerosols within the PBL and is thus more spherical than natural dust. However, we note that approximately $9.6 \%$ of anthropogenic dust is misclassified as natural dust and $8.7 \%$ of natural dust is misidentified as anthropogenic dust within the PBL. Another source of uncertainty in the method comes from the uncertainty in the PBL depth and MODIS land cover. Local anthropogenic dust aerosols from human activities such as agriculture and industrial endeavors contribute $25 \%$ of the global continental dust load. Anthropogenic dust aerosols mainly come from semi-arid and semi-wet regions, which account for more than $52 \%$ of the total anthropogenic dust aerosols.

An analysis of sources over four different continental regions revealed regional characteristics. The annual mean anthropogenic DCB value varies from $0.12 \mathrm{~g} \mathrm{~m}^{-2}$ in North
America to $0.42 \mathrm{~g} \mathrm{~m}^{-2}$ in India. Considering the mean DCB in the four regions, the greatest burden of anthropogenic dust occurs over India, and the greatest burden of natural dust occurs over Africa. On a percentage basis, anthropogenic dust is greatest over eastern China, and natural dust is greater over Africa. Some studies have confirmed that human activities (mainly farming, overgrazing, and water usage) are likely responsible for the expansion of dust sources in northern China and India (Xuan and Sokolik, 2002; Prasad et al., 2007). Igarashi et al. (2011) noted that drought has been a contributing factor. Gong et al. (2004) demonstrated that although desertification has increased by only a few percent in China, it has generated disproportionately large areas of enhanced dust emissions. The relationship between population density and the anthropogenic DCB from our four study regions further supports the above results. As identified in this paper, anthropogenic dust mainly comes from cropland, urban areas, and pastureland. Anthropogenic dust from intermittent dry lake basins is not considered. A major uncertainty in these results comes from the assumption of a single value for the mass extinction efficiency in Eq. (1) that was used in this paper; this parameter probably varies among the different regions. To reduce this uncertainty, it will be necessary to determine different mass extinction efficiencies for natural and anthropogenic dust from different regions. We note that the local anthropogenic dust also affects local climate, air quality, and human health. Therefore, it is necessary to further investigate the interactions among aerosol-cloudprecipitation processes and improve the parameterization of local air pollution effects (Huang et al., 2006a, b, 2010, 2014; Park et al., 2010; Li et al., 2011).

Acknowledgements. Supported by the National Basic Research Program of China (2012CB955301), National Sciences Foundation of China (41305026 \& 41375032), and the China 111 project (No. B 13045). CALIPSO data were obtained from the Atmospheric Sciences Data Center (ASDC) at NASA Langley Research Center. The MODIS data were obtained from the NASA Earth Observing System Data and Information System, and the Land Processes Distributed Active Archive Center (LP DAAC) at the USGS Earth Resources Observation and Science (EROS) Center.

Edited by: D. Covert

\section{References}

Angevine, W. M., White, A. B., and Avery, S. K.: Boundarylayer depth and entrainment zone characterization with a boundary-layer profiler, Bound.-Lay. Meteorol., 68, 375-385, doi:10.1007/BF00706797, 1994.

Bullard, J. E., Harrison, S. P., Baddock, M., Drake, N. A., Gill, T. E., McTainsh, G. H., and Sun, Y.: Preferential dust sources: A geomorphological classification designed for use in global dust-cycle models, J. Geophys. Res., 116, F04034, doi:10.1029/2011JF002061, 2011. 
Chen, B., Huang, J., Minnis, P., Hu, Y., Yi, Y., Liu, Z., Zhang, D., and Wang, X.: Detection of dust aerosol by combining CALIPSO active lidar and passive IIR measurements, Atmos. Chem. Phys., 10, 4241-4251, doi:10.5194/acp-10-4241-2010, 2010.

Chen, S., Huang, J., Zhao, C., Qian, Y., Leung, L. R., and Yang, B.: Modeling the transport and radiative forcing of Taklamakan dust over the Tibetan Plateau: A case study in the summer of 2006, J. Geophys. Res., 118, 797-812, doi:10.1002/jgrd.50122, 2013.

Friedl, M. A., McIver, D. K., Hodges, J. C. F., Zhang, X. Y., Muchoney, D., Strahler, A. H., Woodcocka, C.E., Gopal, S., Schneider, A., Cooper, A., Baccini, A., Gao, F., and Schaaf, C.: Global land cover mapping from MODIS: Algorithms and early results, Remote Sens. Environ., 83, 287-302, 2002.

Friedl, M. A., Sulla-Menashe, D., Tan, B., Schneider, A., Ramankutty, N., Sibley, A., and Huang, X.: MODIS Collection 5 global land cover: Algorithm refinements and characterization ofnew datasets, Remote Sens. Environ., 114, 168-182, doi:10.1016/j.rse.2009.08.016, 2010.

Ginoux, P., Chin, M., Tegen, I., Prospero, J. M., Holben, B., Dubovik, O., and Lin, S. J.: Sources and distributions of dust aerosols simulated with the GOCART model, J. Geophys. Res., 106, 20255-20273, doi:10.1029/2000JD000053, 2001.

Ginoux, P., Prospero, J. M., Gill, T. E., Hsu, N. C., and Zhao, M.: Global-scale attribution of anthropogenic and natural dust sources and their emission rates based on MODIS Deep Blue aerosol products, Rev. Geophys., 50, RG3005, doi:10.1029/2012RG000388, 2012.

Gong, S., Zhang, X., Zhao, T., and Barrie, L.: Sensitivity of Asian dust storm to natural and anthropogenic factors, Geophys. Res. Lett., 31, L07210, doi:10.1029/2004GL019502, 2004.

Herman, J., Bhartia, P., Torres, O., Hsu, C., Seftor, C., and Celarier, E.: Global distribution of UV-absorbing aerosols from Nimbus 7/TOMS data, J. Geophys. Res., 102, 16911-16922, doi:10.1029/96JD03680, 1997.

Hu, Y., Vaughan M., Liu Z., Lin, B., Yang. P., Flittner, D., Hunt, B., Kuehn, R., Huang, J., Wu, D., Rodier, S., Powell, K., Trepte, C., and Winker, D.: The depolarization - attenuated backscatter relation: CALIPSO lidar measurements vs. theory, Opt. Express, 15, 5327-5332, 2007a.

Hu, Y., Vaughan, M., McClain, C., Behrenfeld, M., Maring, H., Anderson, D., Sun-Mack, S., Flittner, D., Huang, J., Wielicki, B., Minnis, P., Weimer, C., Trepte, C., and Kuehn, R.: Global statistics of liquid water content and effective number concentration of water clouds over ocean derived from combined CALIPSO and MODIS measurements, Atmos. Chem. Phys., 7, 3353-3359, doi:10.5194/acp-7-3353-2007, 2007b.

Hu, Y., Winker, D., Vaughan, M., Lin, B., Omar, A., Trepte, C., Flittner, D., Yang, P., Nasiri, S. L., Baum, B., Sun, W., Liu, Z., Wang, Z., Young, S., Stamnes, K., Huang, J., Kuehn, R., and Holz, R.: CALIPSO/CALIOP Cloud Phase Discrimination Algorithm, J. Atmos. Ocean. Tech., 26, 2293-2309, 2009.

Huang, J., Minnis, P., Lin, B., Wang, T., Yi, Y., Hu, Y., SunMack, S., and Ayers, K.: Possible influences of Asian dust aerosols on cloud properties and radiative forcing observed from MODIS and CERES, Geophys. Res. Lett., 33, L06824, doi:10.1029/2005GL024724, 2006a.

Huang, J., Lin, B., Minnis, P., Wang, T., Wang, X., Hu, Y., Yi, Y., and Ayers, J. R.: Satellite-based assessment of possible dust aerosols semi-direct effect on cloud water path over East Asia,
Geophys. Res. Lett., 33, L19802, doi:10.1029/2006GL026561, 2006b.

Huang, J., Ge, J., and Weng, F.: Detection of Asia dust storms using multisensor satellite measurements, Remote Sens. Environ., 110, 186-191, 2007.

Huang, J., Zhang, W., Zuo, J., Bi, J., Shi, J., Wang, X., Chang, Z., Huang, Z., Yang, S., Zhang, B., Wang, G., Feng, G., Yuan, J., Zhang, L., Zuo, H., Wang, S., Fu, C., and Chou, J.: An overview of the semi-arid climate and environment research observatory over the Loess Plateau, Adv. Atmos. Sci., 25, 906-921, doi:10.1007/s00376-008-0906-7, 2008.

Huang, J., Minnis, P., Yan, H., Yi, Y., Chen, B., Zhang, L., and Ayers, J. K.: Dust aerosol effect on semi-arid climate over Northwest China detected from A-Train satellite measurements, Atmos. Chem. Phys., 10, 6863-6872, doi:10.5194/acp-10-68632010, 2010.

Huang, J., Fu, Q., Zhang, W., Wang, X., Zhang, R., Ye, H., and Warren, S. G.: Dust and black carbon in seasonal snow across northern China, B. Am. Meteorol. Soc., 92, 175-181, doi:10.1175/2010BAMS3064.1, 2011.

Huang, J., Guan, X., and Ji, F.: Enhanced cold-season warming in semi-arid regions, Atmos. Chem. Phys., 12, 5391-5398, doi:10.5194/acp-12-5391-2012, 2012.

Huang, J., Wang, T., Wang, W., Li, Z., and Yan, H.: Climate effects of dust aerosols over East Asian arid and semi-arid regions, J. Geophys. Res., 119, 11398-11416, doi:10.1002/2014JD021796, 2014.

Huang, Z., Huang, J., Bi, J., Wang, G., Wang, W., Fu, Q., Li, Z., Tsay, S., and Shi, J.: Dust aerosol vertical structure measurements using three MPL lidars during 2008 China-U.S. joint dust field experiment, J. Geophys. Res., 115, D00K15, doi:10.1029/2009JD013273, 2010.

Huneeus, N., Schulz, M., Balkanski, Y., Griesfeller, J., Prospero, J., Kinne, S., Bauer, S., Boucher, O., Chin, M., Dentener, F., Diehl, T., Easter, R., Fillmore, D., Ghan, S., Ginoux, P., Grini, A., Horowitz, L., Koch, D., Krol, M. C., Landing, W., Liu, X., Mahowald, N., Miller, R., Morcrette, J.-J., Myhre, G., Penner, J., Perlwitz, J., Stier, P., Takemura, T., and Zender, C. S.: Global dust model intercomparison in AeroCom phase I, Atmos. Chem. Phys., 11, 7781-7816, doi:10.5194/acp-11-7781-2011, 2011.

Igarashi, Y., Fujiwara, H., and Jugder, D.: Change of the Asian dust source region deduced from the composition of anthropogenic radionuclides in surface soil in Mongolia, Atmos. Chem. Phys., 11, 7069-7080, doi:10.5194/acp-11-7069-2011, 2011.

Jordan, N. S., Hoff, R. M., and Bacmeister, J. T.: Validation of Goddard Earth Observing System-version 5 MERRA planetary boundary layer heights using CALIPSO, J. Geophys. Res., 115, D24218, doi:10.1029/2009JD013777, 2010.

Justice, C., Kendall, J., Dowty, P., and Scholes, R.: Satellite remote sensing of fires during the SAFARI campaign using NOAA advanced very high resolution radiometer data, J. Geophys. Res., 101, 23851-23863, doi:10.1029/95JD00623, 1996.

Li Z., Li, C., Chen, H., Tsay, S.-C., Holben, B., Huang, J., Li, B., Maring, H., Qian, Y., Shi, G., Xia, X., Yin, Y., Zheng, Y., and Zhuang, G.: East Asian Studies of Tropospheric Aerosols and their Impact on Regional Climate (EAST-AIRC): An overview,J. Geophys. Res., 116, D00K34, doi:10.1029/2010JD015257, 2011. 
Liu, D., Wang, Z., Liu, Z., Winker, D., and Trepte, C.: A height resolved global view of dust aerosols from the first year CALIPSO lidar measurements, J. Geophys. Res., 113, D16214, doi:10.1029/2007JD009776, 2008.

Liu, J., Huang, J., Chen, B., Zhou, T., Yan, H., Jin, H., Huang, Z., and Zhang, B.: Comparisons of PBL heights derived from CALIPSO and ECMWF reanalysis data over China, J. Quant. Spectrosc. Ra., 153, 102-112, doi:10.1016/j.jqsrt.2014.10.011, 2015.

Liu, Z., Vaughan, M. A., Winker, D. M., Hostetler, C. A., Poole, L. R., Hlavka, D., Hart, W., and McGill, M.: Use of probability distribution functions for discriminating between cloud and aerosol in lidar backscatter data, J. Geophys. Res., 109, D15202, doi:10.1029/2004JD004732, 2004.

Liu, Z., Liu, D., Huang, J., Vaughan, M., Uno, I., Sugimoto, N., Kittaka, C., Trepte, C., Wang, Z., Hostetler, C., and Winker, D.: Airborne dust distributions over the Tibetan Plateau and surrounding areas derived from the first year of CALIPSO lidar observations, Atmos. Chem. Phys., 8, 5045-5060, doi:10.5194/acp-85045-2008, 2008.

Liu, Z., Kuehn, R., Vaughan, M., Winker, D., Omar, A., Powell, K., Trepte, C., Hu, Y., and Hostetler, C.: The CALIPSO cloud and aerosol discrimination: Version 3 algorithm and test results, 25th International Laser Radar Conference (ILRC), St. Petersburg, Russia, 5-9, 2010.

Loveland, T. R. and Belward, A. S.: The IGBP-DIS global $1 \mathrm{~km}$ landcover data set, DISCover: First results, Int. J. Remote Sens., 18, 3289-3295, doi:10.1080/014311697217099, 1997.

Mahowald, N. M. and Luo, C.: A less dusty future?, Geophys. Res. Lett., 30, 1903, doi:10.1029/2003GL017880, 2003.

Mahowald, N. M., Zender C. S., Luo, C., Savoie, D., Torres, O., and del Corral, J.: Understanding the 30-year Barbados desert dust record, J. Geophys. Res., 107, D21, doi:10.1029/2002JD002097, 2002.

McGrath-Spangler, E. L. and Denning, A. S.: Estimates of North American summertime planetary boundary layer depths derived from space-borne lidar, J. Geophys. Res., 117, D15101, doi:10.1029/2012JD017615, 2012.

Melfi, S., Spinhirne, J., Chou, S., and Palm, S.: Lidar observations of vertically organized convection in the planetary boundary layer over the ocean, J. Clim. Appl. Meteorol., 24, 806-821, 1985.

Middleton, N.: A geography of dust storms in South-West Asia, J. Climate., 6, 183-196, doi:10.1002/joc.3370060207, 1986.

Mielonen, T., Arola, A., Komppula, M., Kukkonen, J., Koskinen, J., de Leeuw, G., and Lehtinen, K.: Comparison of CALIOP level 2 aerosol subtypes to aerosol types derived from AERONET inversion data, Geophys. Res. Lett., 36, L18804, doi:10.1029/2009GL039609, 2009.

Mitchell, T. D. and Jones, P. D.: An improved method of constructing a database of monthly climate observations and associated high-resolution grids, Int. J. Climatol., 25, 693-712, doi:10.1002/joc.1181, 2005.

Moulin, C. and Chiapello, I.: Evidence of the control of summer atmospheric transport of African dust over the Atlantic by Sahel sources from TOMS satellites (1979-2000), Geophys. Res. Lett., 31, L02107, doi:10.1029/2003GL018931, 2004.

Mulitza, S., Heslop, D., Pittauerova, D., Fischer, H. W., Meyer, I., Stuut, J.-B., Zabel, M., Mollenhauer, G., Collins, J. A., and
Kuhnert, H.: Increase in African dust flux at the onset of commercial agriculture in the Sahel region, Nature, 466, 226-228, doi:10.1038/nature09213, 2010.

New, M., Hulme, M., and Jones, P.: Representing TwentiethCentury Space-Time Climate Variability. Part I: Development of a 1961-90 Mean Monthly Terrestrial Climatology, J. Climate, 12, 829-856, 1999.

Okin, G. S., Bullard, J. E., Reynolds, R. L., Ballantine, J. A. C., Schepanski, K., Todd, M. C., Belnap, J., Baddock, M. C., Gill, T. E., and Miller, M. E.: Dust: Small-scale processes with global consequences, Eos T. Am. Geophys. Un., 92, 241-242, doi:10.1029/2011EO290001, 2011.

Omar, A. H., Winker, D. M., Kittaka, C., Vaughan, M. A., Liu, Z., Hu, Y., Trepte, C. R., Rogers, R. R., Ferrare, R. A., and Lee, K.P.: The CALIPSO automated aerosol classification and lidar ratio selection algorithm, J. Atmos. Ocean. Tech., 26, 1994-2014, doi:10.1175/2009JTECHA1231.1, 2009.

Palm, S. P., Hagan, D., Schwemmer, G., and Melfi, S.: Inference of marine atmospheric boundary layer moisture and temperature structure using airborne lidar and infrared radiometer data, J. Appl. Meteorol., 37, 308-324, doi:10.1175/1520-0450-37.3.308, 1998.

Park, S. H., Gong, S. L., Gong, W., Makar, P. A., Moran, M. D., Zhang, J., and Stroud, C. A.: Relative impact of windblown dust versus anthropogenic fugitive dust in $\mathrm{PM}_{2.5}$ on air quality in North America, J. Geophys. Res., 115, D16210, doi:10.1029/2009JD013144, 2010.

Prasad, A. K., Singh, S., Chauhan, S., Srivastava, M. K., Singh, R. P., and Singh, R.: Aerosol radiative forcing over the IndoGangetic plains during major dust storms, Atmos. Environ., 41, 6289-6301, doi:10.1016/j.atmosenv.2007.03.060, 2007.

Prospero, J. M., Ginoux, P., Torres, O., Nicholson, S. E., and Gill, T. E.: Environmental characterization of global sources of atmospheric soil dust identified with the Nimbus 7 Total Ozone Mapping Spectrometer (TOMS) absorbing aerosol product, Rev. Geophys., 40, 2.1-2.31, doi:10.1029/2000RG000095, 2002.

Qian, W., Quan, L., and Shi, S.: Variations of the Dust Storm in China and its Climatic Control, J. Climate, 15, 1216-1229, 2002.

Sagan, C., Toon, O. B., and Pollack, J. B.: Anthropogenic Albedo Changes and the Earth's Climate, Science, 206, 1363-1368, 1979.

Schneider, A., Friedl, M. A., and Potere, D.: Mapping global urban areas using MODIS 500-m data: New methods and datasets based on "urban ecoregions", Remote Sens. Environ., 114, 17331746, doi:10.1016/j.rse.2010.03.003, 2010.

Sokolik, I. N. and Toon, O. B.: Direct radiative forcing by anthropogenic airborne mineral aerosols, Nature, 381, 681-683, 1996.

Sokolik, I. N., Curry, J., and Radionov, V.: Interactions of Arctic aerosols with land-cover and land-use changes in Northern Eurasia and their role in the Arctic climate system, in: Eurasian Arctic Land Cover and Land Use in a Changing Climate, Springer, 237268, doi:10.1007/978-90-481-9118-5_10, 2011.

Stull, R. B.: An Introduction to Boundary Layer Meteorology, 666 pp., Kluwer Acad., Norwell, Mass, 1988.

Stull, R. B.: Meteorology for Scientists and Engineers, Brooks/Cole, Pacific Grove, Calif., 2000.

Su, Jing, Huang, Jianping, Fu, Qiang, Minnis, P., Ge, Jinming, and Bi, Jianrong: Estimation of Asian dust aerosol effect on cloud radiation forcing using Fu-Liou radiative model and CERES mea- 
surements, Atmos. Chem. Phys., 8, 2763-2771, doi:10.5194/acp8-2763-2008, 2008.

Sun, W., Liu, Z., Videen, G., Fu, Q., Muinonen, K., Winker, D., Lukashin, C., Jin, Z., Lin, B., and Huang, J.: For the depolarization of linearly polarized light by smake particles, J. Quant. Spectrosc. Ra., 122, 233-237, 2013.

Tegen, I. and Fung, I.: Contribution to the atmospheric mineral aerosol load from land surface modification, J. Geophys. Res., 100, 18707-18726, doi:10.1029/95JD02051, 1995.

Tegen, I., Werner, M., Harrison, S., and Kohfeld, K.: Relative importance of climate and land use in determining present and future global soil dust emission, Geophys. Res. Lett., 31, L05105, doi:10.1029/2003GL019216, 2004.

Vaughan, M., Young, S., Winker, D., Powell, K., Omar, A., Liu, Z., $\mathrm{Hu}$, Y., and Hostetler, C.: Fully automated analysis of spacebased lidar data: an overview of the CALIPSO retrieval algorithms and data products, Proc. SPIE Int. Soc. Opt. Eng., 5575, 16-30, 2004.

Wang, X., Zhou, Z., and Dong, Z.: Control of dust emissions by geomorphic conditions, wind environments and land use in northern China: An examination based on dust storm frequency from 1960 to 2003, Geomorphology, 81, 292-308, doi:10.1016/j.geomorph.2006.04.015, 2006.
Winker, D. M., Hunt, W. H., and McGill, M. J.: Initial performance assessment of CALIOP, Geophys. Res. Lett., 34, L19803, doi:10.1029/2007GL030135, 2007.

Xuan, J. and Sokolik, I. N.: Characterization of sources and emission rates of mineral dust in Northern China, Atmos. Environ. 36, 4863-4876, doi:10.1016/S1352-2310(02)00585-X, 2002.

Young, S. A. and Vaughan, M. A.: The Retrieval of Profiles of Particulate Extinction from Cloud-Aerosol Lidar Infrared Pathfinder Satellite Observations (CALIPSO) Data: Algorithm Description, J. Atmos. Ocean. Technol., 26, 1105-1119, doi:10.1175/2008JTECHA1221.1, 2009.

Yu, H., Remer, L. A., Chin, M., Bian, H., Tan, Q., Yuan, T., and Zhang, Y.: Aerosols from overseas rival domestic emissions over North America, Science, 337, 566-569, doi:10.1126/science.1217576, 2012. 